\title{
Discrimination of simultaneous and successive tones'
}

DOHALO G. DOEHRIHG ${ }^{2}$

MCGILL UNIVERSITY

A series of discrimination tasks involving simultaneous and successive presentation of pairs of piano notes was given to $27 \mathrm{Ss}$. The listeners exhibited less-than-perfect ability to "hear out" the component notes in simultaneous presentations. This finding, in agreement with the results of previous investigators, demonstrated the limitation of Ohm's law of acoustical analysis. It was also found that changes in successive notes following simultaneous notes were discriminated more accurately than changes in simutaneous notes following successive notes. This was interpreted as suggesting that listeners are better able to analyze than to synthesize the components of complex tones.

A mixture of two or more colors is usually seen as a single color. When two or more tones are mixed, however, the listener may be able to identify the components of the complex sound. According to Ohm's acoustical law, a complex sound is perceived by analysis into its component tones (von Bekesy, 1960). This law has been tested in several ways. Thurlow and Rawlings (1959) asked listeners to judge the number of tones in a complex sound. Pollack (1964) investigated the ability of listeners to recognize individual tones in simultaneous and successive tonal combinations. Plomp (1964) required the listener to judge which of two tones was contained in a complex tone. By each of these procedures the ability of the $O$ to perform the frequency analysis postulated by Ohm's law was somewhat less than perfect.

An important aspect of research into the perception of complex sounds is the method by which the $S$ is asked to demonstrate his ability to "hear out" the components of a complex sound. In the present study the auditory stimuli were pairs of piano notes played together or played separately. The listener was asked to judge whether two pairs of notes contained the same notes. This judgment was made where the notes of each pair were played together, where the notes of each pair were played separately, where notes played separately were followed by notes played together, and where notes played together were followed by notes played separately.

\section{METHOD}

\section{Subjects}

Subjects were 8 males and 19 females ranging in age from 11 to 54, in musical experience from no formal instruction to 11 years of piano instruction, and in education from 5 to 19 years. All had normal hearing.

\section{Apparatus}

Tonal stimuli were played on a Hardman Peck baby grand piano and recorded on an RCA Victor model 7-TR-3 tape recorder with a dynamic microphone. The microphone was positioned on the closed lid of the piano over the center of the action for the middle octave. Test materials were presented via a sony model TC-135 tape recorder and Pioneer SE-21 stereophonic earphones modified for monophonic reproduction.

\section{Test Stimuli}

The four conditions of stimulus presentation are summarized in Table 1. Simultaneous stimuli were two notes played together for $1 / 2 \mathrm{sec}$. Successive stimuli were two successive $1 / 2 \mathrm{sec}$ notes. The interval between the first pair of notes (Stimulus 1) and the second pair of notes (Stimulus 2) was $1 \mathrm{sec}$. The number of the trial was spoken $4 \mathrm{sec}$ before Stimulus 1 , and the interval between trials was $4 \mathrm{sec}$. All test stimuli were recorded at approximately the same level, as indicated by the VU meter of the tape recorder, with the individual notes of a stimulus played at about the same loudness.

There were 24 trials under each of the four conditions. On 12 of the trials Stimulus 1 contained the same notes as Stimulus 2, and would be correctly judged as "same." On the remaining 12 trials one of the notes of Stimulus 2 differed from the corresponding note of Stimulus 1 by one semitone ( $1 / 12$ of an octave), and would be correctly judged as "different."

The piano notes ranged in fundamental frequency from $139 \mathrm{~Hz}$ (C-sharp below middle C) to $1661 \mathrm{~Hz}$ (G-sharp in the second octave above middle $\mathrm{C}$ ). Within each condition there were eight trials each in which the low note of Stimulus 1 was played in the octave

Table 1. Summary of the Four Conditions of Stimulus Presentation

\begin{tabular}{|c|c|c|}
\hline Condition & Stimulus 1 & Stimulus 2 \\
\hline 1. & $\begin{aligned} & \text { simultoneous: } \text { high note) } \\
& \text { low note) }\end{aligned}$ & $\begin{array}{r}\text { simultaneous: high note) } \\
\text { low note })\end{array}$ \\
\hline 11. & $\begin{array}{l}\text { successive: } \\
\quad \text { low note-high note }\end{array}$ & $\begin{array}{l}\text { successive: } \\
\text { low note-high note }\end{array}$ \\
\hline 111. & $\begin{array}{l}\text { successive: } \\
\text { low note-high note }\end{array}$ & $\begin{array}{r}\text { simultaneous: high note) } \\
\text { low note) }\end{array}$ \\
\hline IV. & $\begin{array}{r}\text { simultaneous: high note) } \\
\text { low note) }\end{array}$ & $\begin{array}{l}\text { successive: } \\
\text { low note-high note }\end{array}$ \\
\hline
\end{tabular}


below middle $C$, the octave beginning with middle $C$, and the octave beginning with $\mathrm{C}$ above middle $\mathrm{C}$. The low note and the high note of Stimulus 1 were separated by 4,7 , or 11 semitones on eight trials each within each condition. For the 12 "different" trials in each condition, the low note of Stimulus 2 was changed by one semitone and the high note by one semitone on six trials each. The note changed in Stimulus 2 was one semitone higher on six trials and one semitone lower on the remaining six trials. The above variables were systematically balanced within each condition, and the order of trials was randomized.

\section{Procedure}

Subjects were tested individually in a quiet room, with test material played at a comfortable listening level. Recorded instructions which included an example of the test stimuli were given before the beginning of each series. The $S$ responded on each trial by marking $S$ (same) or D (different), and received no information regarding correctness of judgment. The four conditions were given in the order $1,2,3,4$ to $13 \mathrm{Ss}$, and in the order $2,1,4,3$ to 14 Ss.

The Timbre and Tonal Memory subtests of the Seashore Measures of Musical Talent (Seashore et al, 1960) were also given to all Ss. These tests were administered in the prescribed manner, except that test material was presented via a dubbed tape recording and earphones instead of the usual free-field presentation from phonograph records.

\section{RESULTS}

Table 2 shows the percentage of correct responses made by the 27 Ss under the various conditions. A number of statistical comparisons were made between methods of presentation and within the parameters listed in the left-hand column of Table 2. The signed rank test for paired observations was used in compari- sons involving two sets of measures, and the analysis of variance by ranks was used for comparisons involving three sets of measures (Walker \& Lev, 1953).

Accuracy of discrimination was well above the chance level of $50 \%$ under all conditions. The listeners wers significantly more accurate (.01 level) in discriminating between two pairs of successive notes (Condition 2) than between two pairs of simultaneous notes (Condition 1). Combined scores on Conditions 1 and 2 were significantly better (.01 level) than combined scores under the two conditions ( 3 and 4) which involved mixed modes of presentation, despite the possibility of practice effect resulting from Conditions 3 and 4 always being presented after Conditions 1 and 2. Condition 3, where successive notes were followed by simultaneous notes, was significantly more difficult (.05 level) than Condition 4, where simultaneous notes were followed by successive notes. Comparisons between Conditions 1 and 2 and between Conditions 3 and 4 did not involve order effects, since, as mentioned previously, the order $1,2,3,4$ was used for $13 \mathrm{Ss}$ and the order $2,1,4,3$ for 14 Ss.

Discrimination was significantly poorer (.01 level) on trials where the correct response was different (D), indicating a consistently conservative tendency to respond same (S) on doubtful trials rather than random guessing. The trend occurred under all conditions, and was most marked under Condition 3 , the most difficult mode of presentation.

Accuracy of discrimination varied significantly (.02 level) as a function of the difference in semitones between the two notes of Stimulus 1 . This significant effect resulted from poorer discrimination of the 11-semitone difference, a trend which occurred under all conditions.

The octave in which the low note was played did not significantly affect accuracy, with only a weak

Table 2. Percentage of Correct Responses Under Each Condition for the 27 Ss

\begin{tabular}{|c|c|c|c|c|c|}
\hline & $\begin{array}{l}1 \\
\text { Simultaneous. } \\
\text { simultaneous } \\
(24 \text { trials })\end{array}$ & $\begin{array}{l}\text { II } \\
\text { Successive- } \\
\text { successive } \\
(24 \text { trials) }\end{array}$ & $\begin{array}{l}\text { III } \\
\text { Successive- } \\
\text { simultaneous } \\
(24 \text { trials })\end{array}$ & $\begin{array}{l}\text { IV } \\
\text { Simultoneous - } \\
\text { successive } \\
(24 \text { trials })\end{array}$ & $\begin{array}{l}\text { Total } \\
\text { (96 trials) }\end{array}$ \\
\hline All trials & 84 & 89 & 74 & 78 & 81 \\
\hline $\begin{array}{l}\text { "same" trials } \\
\text { "different" trials }\end{array}$ & $\begin{array}{l}87 \\
81\end{array}$ & $\begin{array}{l}91 \\
86\end{array}$ & $\begin{array}{l}83 \\
66\end{array}$ & $\begin{array}{l}83 \\
73\end{array}$ & $\begin{array}{l}86 \\
76\end{array}$ \\
\hline $\begin{array}{l}4 \text { semitones between high and low note } \\
7 \text { semitones between high and low note } \\
11 \text { semitones between high and low note }\end{array}$ & $\begin{array}{l}83 \\
88 \\
80\end{array}$ & $\begin{array}{l}89 \\
92 \\
86\end{array}$ & $\begin{array}{l}79 \\
74 \\
71\end{array}$ & $\begin{array}{l}80 \\
77 \\
76\end{array}$ & $\begin{array}{l}83 \\
83 \\
78\end{array}$ \\
\hline $\begin{array}{l}\text { Low note in high octave } \\
\text { Low note in middle octave } \\
\text { Low note in low octave }\end{array}$ & $\begin{array}{l}85 \\
82 \\
84\end{array}$ & $\begin{array}{l}92 \\
87 \\
87\end{array}$ & $\begin{array}{l}75 \\
73 \\
75\end{array}$ & $\begin{array}{l}76 \\
76 \\
81\end{array}$ & $\begin{array}{l}82 \\
80 \\
82\end{array}$ \\
\hline $\begin{array}{l}\text { High note changed on "different" trials } \\
\text { Low note changed on "different" trials }\end{array}$ & $\begin{array}{l}83 \\
79\end{array}$ & $\begin{array}{l}89 \\
84\end{array}$ & $\begin{array}{l}72 \\
60\end{array}$ & $\begin{array}{l}80 \\
66\end{array}$ & $\begin{array}{l}81 \\
72\end{array}$ \\
\hline $\begin{array}{l}\text { One semitone higher on "different" trials } \\
\text { One semitone lower on "different" trials }\end{array}$ & $\begin{array}{l}74 \\
88\end{array}$ & $\begin{array}{l}88 \\
85\end{array}$ & $\begin{array}{l}64 \\
68\end{array}$ & $\begin{array}{l}72 \\
73\end{array}$ & $\begin{array}{l}74 \\
78\end{array}$ \\
\hline $\begin{array}{l}\text { First } 12 \text { triols } \\
\text { Last } 12 \text { trials }\end{array}$ & $\begin{array}{l}86 \\
82\end{array}$ & $\begin{array}{l}88 \\
90\end{array}$ & $\begin{array}{l}77 \\
72\end{array}$ & $\begin{array}{l}78 \\
78\end{array}$ & $\begin{array}{l}82 \\
80\end{array}$ \\
\hline
\end{tabular}


suggestion of poorer accuracy for the middle octave. Discrimination was significantly poorer (.01 level) when the low note of Stimulus 2 was changed on D trials. This effect was most pronounced under Conditions 3 and 4. However, the Ss' performance was not significantly affected by whether the note changed was increased or decreased by one semitone.

Practice effects were assessed by comparison of the first and the last 12 trials. If anything, accuracy tended to decrease slightly over trials, suggesting that task performance was not hampered by a lack of extensive pretraining.

Intercorrelations among the four modes of stimulus presentation and the two Seashore tests, as assessed by the Spearman rank correlation coefficient corrected for ties (Siegel, 1956), are shown in Table 3. Significant positive correlations were found in all but three cases. Although only limited inferences are possible with regard to the relative magnitude of correlation coefficients, two comparisons are worthy of note. The correlations of .69 between 1 and 2 and .90 between 3 and 4 were considerably higher than the remaining correlations among these four measures. Condition 3 was highly correlated with the Timbre test but not the Tonal Memory Test, while Condition 4 was highly correlated with Tonal Memory but not with Timbre.

The rank correlation between age and total correct responses over the four conditions was .27 (not significant), and the correlation between total correct responses and number of years of musical experience was .37 (.05 level).

\section{DISCUSSION}

Some form of acoustical analysis was presumably required for three of the four modes of stimulus presentation in the present study. Accuracy of discrimination was better than chance under all three conditions. However, accuracy was even greater under the remaining condition, where successive tones were discriminated. This finding was in agreement with the results of Pollack (1964) and can be interpreted in the same manner, as demonstrating a limitation in the ability to hear out the components of complex tones.

In Pollack's study the listener was required to discriminate a single component of complex tones or tonal sequences made up of two, three, or four com-

Table 3. Intercorrelations Among the Four Modes of Stimulus Presentation and the Seashore Timbre and Tonal Memory Tests

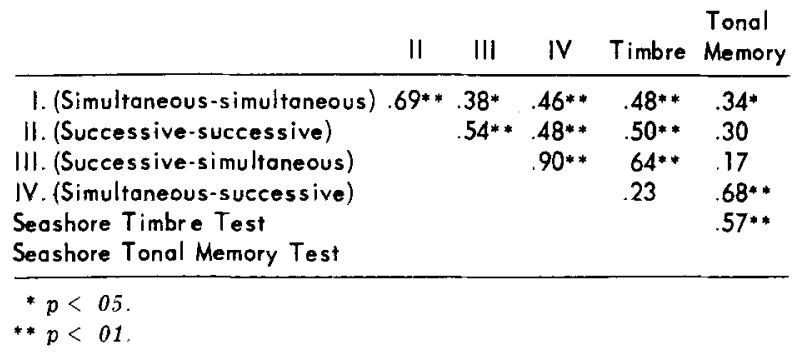

ponent tones. For the two-component tones his listeners exhibited $64 \%$ accuracy for simultaneous and $84 \%$ accuracy for successive tones. In the present study the per cent correct was $84,74,78$ for the simultaneous-note conditions, as compared with 89 for the successive-note conditions. The greater accuracy for the simultaneous condition in this study is probably attributable to procedural differences and differences in test stimuli between the two studies. The piano notes used in this study were complex stimuli in themselves, and the tonal variation on $D$ trials was always a semitone. In Condition 1 the discrimination between two simultaneous tones could have been based upon an unanalyzed spectral configuration. In Conditions 3 and 4 , however, a response to the two separate components of the complex tone was required, in contrast to the discrimination of a single component in Pollack's study. The timing of stimulus presentation may have also contributed to differences between the two studies.

In Conditions 1 and 2 of the present study both stimuli were either simultaneous or successive, whereas Conditions 3 and 4 involved a mixed presentation of simultaneous and successive notes. Although the greater accuracy under the simpler modes of presentation can be explained on other grounds, it is interesting to consider the possible effect of task simplicity. The relatively high correlations between Conditions 1 and 2 and between Conditions 3 and 4 indicate that somewhat different types of ability may be required for the simple and mixed modes of presentation. Acoustical analysis may involve more than one type of skill, and the efficiency of analysis may be related to individual differences in these abilities.

The difference in accuracy between Conditions 3 and 4 was relatively small, but statistically significant. It was easier for the Ss to "take apart" the simultaneous tone in the subsequent discrimination of the successive tone under Condition 4 than to "put together" the successive tone in the subsequent discrimination of the simultaneous tone under Condition 3 . In this sense, tonal analysis may be more efficient than tonal synthesis. Pollack reported similar results for a "negative latency" condition, where the single probe tone preceded the complex tone. Accuracy was $3 \%$ poorer under this condition, which corresponded to Condition 3 , than under the usual sequence of presentation, which corresponded to Condition 4 .

The high correlations of Condition 3 with the Seashore Timbre test and of Condition 4 with the Seashore Tonal Memory test are also indicative of differences between these two modes of presentation. The synthetic task in Condition 3 was related to the ability to discriminate slight changes in the intensity of overtones in a complex tone on the Timbre test, and the analytic task in Condition 4 was related to the ability to identify the note varied in a tonal sequence on the Tonal Memory test. These relationships, which seem somewhat paradoxical, may indicate that the most difficult aspect of 
the synthetic process in Condition 3 is the hearing out of the simultaneous tones of the second stimulus, and the most difficult part of the analytic process in Condition 4 is "hearing together" the separate notes of the second stimulus. The use of stimuli with more than two components would help to clarify the comparison of these two modes of presentation.

Since accuracy was poorest for notes separated by 11 semitones, judgments of the more closely-spaced notes were probably not seriously hampered by masking. Even where the notes were separated by only four semitones the difference in fundamental frequencies exceeded the critical bands for two-tone signals reported by Plomp (1964). Poor discrimination with the 11semitone separation of notes could be accounted for by the smaller relative change in the fundamental frequency difference between the two notes on $\mathrm{D}$ trials, $1 / 11$ rather than $1 / 4$ or $1 / 7$. If so, the discrimination was based upon something more than an analysis of of isolated components of the auditory stimulus. Music habits may have contributed to difficulty with the 11semitone separation. In musical terminology the 4semitone difference is a major third, the 7-semitone difference a perfect fifth, and the 11-semitone difference a major seventh interval. The major seventh interval has been rated as much less consonant (more dissonant) than the major third and the perfect fifth (Seashore, 1938), a characteristic which could be associated with the ability to discriminate changes in the width of tonal intervals.

Discrimination was poorer when the low note of Stimulus 2 was varied on D trials, even though the relative change in fundamental frequency was about the same for low and high notes. This effect could be associated with the fixed order-low note followed by high note-in successive stimuli, although the effect also occurred in Condition 1, where both stimuli were simultaneous. Habits of attending to the melodic line in piano compositions could lead to a more accurate discrimination of changes in the high note. The use of complex tones with more than two components would provide further information.

The present study differed from previous studies in using a group of Ss with a relatively wide range of age and listening experience. The consistency of observed trends, along with the absence of high correlations involving age and musical experience, suggests that uniform habits of listening to complex sounds and tonal sequences can be developed under a variety of environmental circumstances.

The human listener does not have the ability to function as a perfect frequency analyzer. As Pollack (1964) has pointed out, the ear seems to operate as an excellent wave analyzer in comparison to the eye, but its analytic capacities do not equal its ability to respond to tonal sequences. Ward (in press) describes "Ohm's Other Law" as a quarter-truth. He gives examples of imperfect acoustical analysis in musical perception and states that distortion introduced at various stages of the auditory system precludes the possibility of a perfect Fourier analysis by the human listener.

Our understanding of the perception of complex sounds is still limited. The results of the present study suggest several lines of investigation. The perception of simultaneous and successive tones can be compared in a more precise manner by systematic variation of the temporal relationships of tonal components. The abilities to analyze complex tones into tonal sequences can be further investigated by the use of complex tones with varying numbers of components. Individual differences in the various abilities which are involved in tonal analysis should be further studied, and the upper limits of these abilities determined by systematic training procedures.

Since complex sounds are not perfectly analyzed in the elegant manner prescribed in Ohm's acoustical law, a major task of future research is specification of the additional factors which enter into the listeners response.

\section{References}

Plomp. R. The ear as a frequency analyzer. J. Acoust. Soc. Amer. 1964, 36. 1628-1636

Pollack. I. Ohm's acoustical law and short-term auditory memory. J. Acuust. Sac. Amer., 1964, 36, 2340-2345.

Seashore, C. E. Psychology of music. New York: McGraw-Hill, 1938

Seashore, C. E., Lewis, D., \& Saetveit, J. G. Seashore measures of musical talent (Rev. ed.). New York: The Psychological Corporation, 1960.

Seigel, S. Nonparametric statistics for the bchazioral sciences. New York: McGraw-Hill, 1956.

Thurlow, W. R., \& Rawlings, I. L. Discrimination of number of simultaneous sounding tones. J. Acoust. Soc. Amer., 1959 , 31. 1332- 1336 .

Von Bekésy, G. Experiments in hearing. New York: McGraw-Hill, 1960.

Walker, H. M., \& Lev, J. Statistical infercnce. New York: Henry Holt, 1953.

Ward, W. D. Musical perception. In J. V. Tobias \& E. Schubert (Eds.), Foundations of modern auditory theory. New York: Academic Press, in press.

\section{Notes}

1. This research was supported by Grants MA-1652 from the Medical Rescarch Council of Canada and 604-7-507 from the Canadian Department of National Health and Welfare.

2. The writer wishes to thank Dr. Linda Swisher for help in planning and carrying out this research, and Mr. and Mrs. Daniel Ling for comments on the manuscript.

(Accepted for puhlication December 1, 1967.) 